\title{
The Cardiopulmonary Effects of Calcium Infusion in Infants with Persistent Pulmonary Hypertension of the Newborn
}

\author{
ELLEN BIFANO, RAE-ELLEN KAVEY, JAMES PERGOLIZZI, TERRI SLAGLE, AND \\ WILLIAM BERGSTROM
}

State University of New York, Health Science Center at Syracuse, Syracuse, New York 13210

\begin{abstract}
Low blood ionized calcium levels have been reported previously in association with alkalosis in infants undergoing hyperventilation for persistent pulmonary hypertension. We investigated the effect of acute calcium infusions on the cardiopulmonary status of 10 hypocalcemic, hyperventilated infants with persistent pulmonary hypertension. Acid-base status, arterial partial pressure of oxygen, vital signs, and echocardiographically determined right and left systolic time interval ratios and left ventricular shortening fractions were obtained before and after rapid infusions of calcium gluconate or saline. At 5 and 15 min after calcium infusion, but not after saline infusion, there were significant decreases in both right and left ventricular systolic time interval ratios, and an increase in transcutaneous $\mathrm{PO}_{2}$ and $\mathrm{PaO}_{2}$ that coincided with peak levels of ionized calcium. These findings provide evidence that high levels of ionized calcium in newborns with persistent pulmonary hypertension transiently improve myocardial performance and oxygenation. (Pediatr Res 25:262-265,1989)
\end{abstract}

Abbreviations

PPHN, persistent pulmonary hypertension of the newborn $\mathrm{TcPO}_{2}$, transcutaneous $\mathrm{PO}_{2}$

PPHN is a cause of severe hypoxia related to elevated pulmonary vascular resistance and right to left shunting across fetal circulatory channels. The majority of infants with PPHN have a clinical history of perinatal asphyxia (1). Many of these infants also have evidence of myocardial dysfunction. Treatment of PPHN is directed at lowering pulmonary vascular resistance while maintaining systemic blood pressure. Hyperventilationinduced alkalosis is used commonly to lower pulmonary vascular resistance; it is often necessary to raise the $\mathrm{pH}$ to $\geq 7.55$ to lower pulmonary artery pressures (2). We have shown that this degree of alkalosis substantially lowers blood ionized calcium levels in hyperventilated infants with PPHN (3). Although it has been theorized that low blood ionized calcium may in part mediate the decline in pulmonary vascular resistance with hyperventilation, hypocalcemia may worsen the already impaired myocardial function of infants with pulmonary hypertension (4-7). The present study was designed to assess the effects of ionized calcium infusion on echocardiographically determined cardiac perform-

Received July 6, 1988; accepted October 28, 1988

Correspondence and reprint requests Ellen M. Bifano, M.D., Department of Pediatrics, SUNY, Health Science Center at Syracuse, 750 E. Adams Street, Syracuse, NY 13210. ance and peripheral oxygenation in hypocalcemic infants with PPHN undergoing treatment with hyperventilation.

\section{MATERIALS AND METHODS}

Subjects were selected from infants admitted to the Crouse Irving Memorial Hospital Intensive Care Nursery between December 1984 and February 1986. The diagnosis of PPHN was made in infants of greater than $37 \mathrm{wk}$ of gestational age with severe respiratory distress who met the following criteria:1) a $\mathrm{PaO}_{2}$ of less than 60 torr while breathing $100 \%$ oxygen, 2) an increase in $\mathrm{PaO}_{2}$ to more than 100 torr during hyperventilation with $100 \%$ oxygen, and 3) the presence of prolonged right and left ventricular systolic time interval rations. No infants selected had hematocrits $>60 \%$, clinical evidence of pulmonary hypoplasia or structural heart disease.

Infants with PPHN were enrolled in the study when they met the following additional criteria: $l$ ) postnatal age less than $72 \mathrm{~h}$, 2) need for hyperventilation with an arterial $\mathrm{pH} \geq 7.50,3$ ) cardiopulmonary stability for at least $2 \mathrm{~h}$ with no greater than a $15 \%$ fluctuation in oxygenation, $\mathrm{pH}$, or vital signs, 4) whole blood ionized calcium level $\leq 3 \mathrm{mg} / \mathrm{dl}$ and 5 ) no previous treatment with tolazoline. Patients were assigned randomly either to receive calcium infusion first, followed $1 \mathrm{~h}$ and $10 \mathrm{~min}$ later by normal saline, or to receive saline first followed by calcium. Calcium was administered through umbilical arterial catheters as $10 \%$ calcium gluconate at a dose of $200 \mathrm{mg} / \mathrm{kg}$ over a period of $2 \mathrm{~min}$; normal saline was given similarly and in the same vol $(2 \mathrm{ml} / \mathrm{kg})$. Heart rate, blood pressure, $(\mathrm{TcPO})$, arterial blood gases, and total serum and plasma ionized calcium, and phosphorus were secured $10 \mathrm{~min}$ before and 5, 35, and $55 \mathrm{~min}$ after each infusion. M-mode echocardiograms were recorded at the same time intervals using a Hoffrel System 202 (Hoffred Instruments, Greenwich, CT) with simultaneous electrocardiogram and a $5 \mathrm{mHz} / 6 \mathrm{~mm}$ nonfocused transducer on light-sensitive paper as previously described $(8,9)$. Previous studies have documented the accuracy of echocardiographically determined right and left ventricular systolic time intervals (i.e. the ratio of the preejection period to ventricular ejection time of the right and left ventricle) and indices of left ventricular performance in both static and changing hemodynamic states $(10,11)$. Although the right and left systolic time interval ratios are not accurate indices of pulmonary arterial pressure and/or pulmonary vascular resistance, they have been shown to identify infants with PPHN (8). The right and left systolic time interval ratios and shortening fractions of the left ventricle were the means of at least three determinations by one of the authors (R.K.) blinded to study infusion. The velocity of circumferential fiber shortening, an index of myocardial function, was calculated from the ratio of the fiber shortening index to left ventricular ejection time (12). Our normal values in term newborns for these echocardiographic 
parameters are: right ventricular systolic time interval, $\leq 0.3$; left ventricular systolic time interval, $0.32-0.39$; shortening fraction of the left ventricle, $0.27-0.39$; and velocity of circumferential fiber shortening of the left ventricle, $1.2 \pm 0.2$ circumferences $/ \mathrm{s}$.

Blood for ionized calcium measurements was collected in heparinized syringes without exposure to air and performed in duplicate using a Radiometer flow-through ion electrode (Radiometer America, Inc., Westlake, $\mathrm{OH}$ ) (3). The normal value for plasma ionized calcium in term infants at $48 \mathrm{~h}$ of age is $4.6 \pm$ $0.10 \mathrm{mg} / \mathrm{dl}$ with a coefficient of variation of less than $2 \%$. Total serum calcium was determined by EDTA titration (13) and serum phosphorus by a modification of the method of FiskeSubarow (14).

Echocardiographic, physiologic, and biochemical data at each time period were compared with baseline values before calcium or saline infusion. Data were evaluated by ANOVA using the Method of Fitting Constants followed by Dunnett's $t$ test. All data are presented as the mean \pm SEM.

\section{RESULTS}

Six males and four females were studies. Their mean gestational age was $39 \mathrm{wk}$ (range $37-41 \mathrm{wk}$ ) and mean birth wt was $3237 \mathrm{~g}$ (range $2120-4460 \mathrm{~g}$ ). Six infants had the diagnosis of persistent fetal circulation with a clear chest radiograph, three infants had pulmonary hypertension associated with aspiration of meconium or amniotic fluid, and one infant had group B streptococcal sepsis. All babies were paralyzed with pancuronium bromide and hyperventilated with $\mathrm{pH}$ between 7.50 and 7.67. All infants received $10-20 \mu \mathrm{g} / \mathrm{kg} / \mathrm{min}$ of dopamine to maintain systolic blood pressure $>60$ torr. The mean age at the time of study was $38 \pm 16 \mathrm{~h}$. Five infants received normal saline first and five infants received calcium first. There were no complications of either infusion.

Table 1 shows the changes in total serum calcium and phosphorus and plasma ionized calcium after infusion of calcium. At $5 \mathrm{~min}$ after calcium infusion, total and ionized calcium increased $6.7 \pm 0.3$ and $3.5 \pm 0.3 \mathrm{mg} / \mathrm{dl}$ above baseline, respectively $(p<$ $0.01)$, and both remained significantly elevated for $55 \mathrm{~min}$ after infusion $(p<0.01)$. Phosphorus levels were unchanged after calcium infusion. Before saline infusion, baseline values of total calcium, ionized calcium, and phosphorus were $7.1 \pm 0.4,2.9 \pm$ 0.2 , and $3.4 \pm 0.3 \mathrm{mg} / \mathrm{dl}$, respectively. There were no changes in these values $5,15,35$, and 55 min after saline infusion (data not shown).

Figure 1 compares the echocardiographic changes with changes in ionized calcium after infusion of calcium and saline. The right and left ventricular systolic time interval ratios are represented as the mean change from preinfusion values. The mean baseline values for right and left ventricular systolic time interval ratios were $0.53 \pm 0.07$ and $0.55 \pm 0.07$, respectively. At 5 and 15 min after calcium infusion, there were significant decreases in both systolic time interval ratios that coincided with peak levels of

Table 1. Effect of calcium infusion on total serum calcium, plasma ionized calcium, and serum phosphorus in infants with PPHN*

\begin{tabular}{cccccc}
\hline & \multicolumn{5}{c}{ Time in relation to calcium infusion } \\
& -10 & 5 & 15 & 35 & 55 \\
\hline & 7.1 & $13.8 \dagger$ & $11.4 \dagger$ & $9.7 \dagger$ & $9.2 \dagger$ \\
Total calcium $(\mathrm{mg} / \mathrm{dl})$ & $(0.3)$ & $(0.4)$ & $(0.5)$ & $(0.4)$ & $(0.5)$ \\
& 2.6 & $6.1 \dagger$ & $5.1 \dagger$ & $4.2 \dagger$ & $3.7 \dagger$ \\
Ionized calcium (mg/dl) & $(0.1)$ & $(0.3)$ & $(0.3)$ & $(0.3)$ & $(0.2)$ \\
& 3.4 & 3.7 & 3.8 & 3.8 & 3.9 \\
Phosphorus (mg/dl) & $(0.3)$ & $(0.2)$ & $(0.4)$ & $(0.3)$ & $(0.4)$ \\
\hline
\end{tabular}

* All values are the mean \pm SEM.

$\dagger p<0.01$ compared to $-10 \mathrm{~min}$ value.

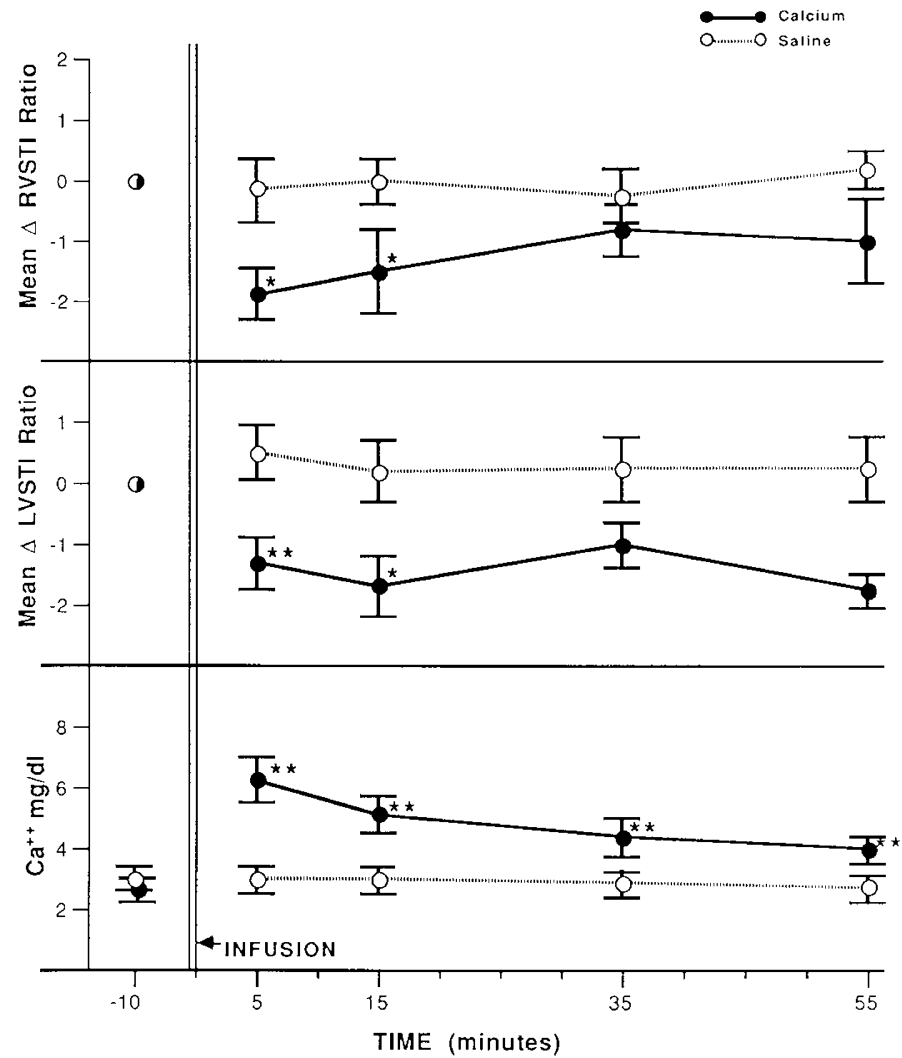

Fig. 1. Mean change of right ventricular systolic time interval (upper) and left ventricular systolic time interval (middle) ratios and levels of ionized calcium (lower) after Ca gluconate or normal saline. Each point represents the mean \pm SEM from -10 min baseline values. ${ }^{*} p<0.05$; $* * p<0.01$ from baseline values.

ionized calcium. The decreases in right and left systolic time interval ratios resulted primarily from shortening of the preejection periods. The right ventricular preejection period declined from a baseline mean of $0.074 \pm 0.005 \mathrm{~s}$ to $0.052 \pm 0.003 \mathrm{~s}$ at 5 $\min (p<0.01)$ and $0.057 \pm 0.005 \mathrm{~s}$ at $15 \mathrm{~min}(p<0.05)$ after calcium infusion. The left ventricular preejection period dropped from a baseline mean of $0.070 \pm 0.007 \mathrm{~s}$ to $0.054 \pm 0.006 \mathrm{~s}$ at 5 $\min (p<0.01)$ and $0.056 \pm 0.007 \mathrm{~s}$ at $15 \mathrm{~min}(p<0.05)$ after calcium infusion. There were no significant changes in ejection times. Calcium infusion had no effect on the shortening fraction of the left ventricle $(0.25 \pm 0.08)$ or the velocity of circumferential fiber shortening $(2.2 \pm 0.3$ circumferences/s). Saline had no effect on any echocardiographic parameter.

Figure 2 compares changes in $\mathrm{TcPO}_{2}, \mathrm{PaO}_{2}$, and ionized calcium levels before and after calcium infusion. The mean baseline value for $\mathrm{TcPO}_{2}$ before calcium and saline infusions was $150 \pm$ $40 \mathrm{~mm} \mathrm{Hg}$, and the preinfusion value for $\mathrm{PaO}_{2}$ was $168 \pm 47$ $\mathrm{mm} \mathrm{Hg}$. Coincident with the rise in ionized calcium and change in cardiac performance was a statistically significant rise in oxygenation. The mean rise in $\mathrm{TcO}_{2}$ level was 47 torr, 5 min after infusion; this preceded the peak rise in arterial oxygenation of 42 torr, 15 min after calcium infusion. Although, the values remained above baseline, the increase in oxygenation was no longer significantly different 35 and $55 \mathrm{~min}$ after infusion.

Calcium and saline infusion had no effect on blood pressure, heart rate, or blood $\mathrm{pH}$.

\section{DISCUSSION}

Bolus calcium infusion in hypocalcemic infants with PPHN did not reverse the pulmonary vasodilating effects of alkalosis, but resulted in improved oxygenation and decreased right and left ventricular systolic time interval ratios. These cardiovascular 


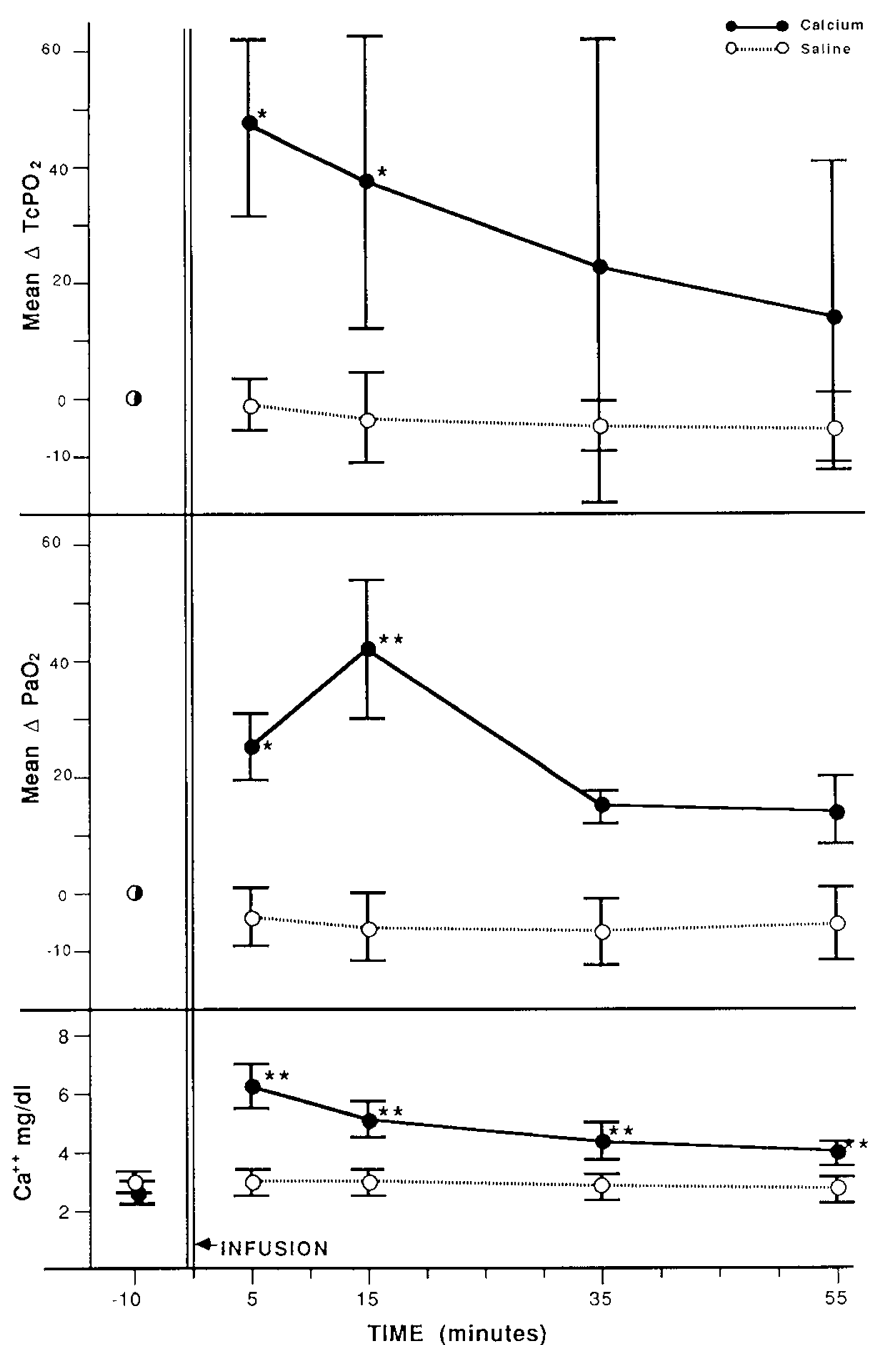

Fig. 2. Mean change in $\mathrm{TcPO}_{2}$ (upper), $\mathrm{PaO}_{2}$ (middle), and ionized calcium levels (lower) after calcium or saline infusions. Each point represents the mean $\pm \mathrm{SEM}$ from each -10 min value. ${ }^{*} p<0.05 ;{ }^{* *} p$ $<0.01$ from baseline values.

effects were not attributable to vol expansion as isovolemic infusions of saline had no effect. These changes could be due to improved myocardial contractility, a decrease in electromechanical delay and/ or a decrease in total vascular resistance (afterload). In the absence of alterations in myocardial contractility, the pressure in the aorta or pulmonary artery determine the systolic time intervals, and a decline in the diastolic pressure in the vessel is reflected in shortening of the preejection period. However, when this principle has been applied to the clinical circumstance of infants with PPHN where there may be impaired contractility, alterations in interval ratios often do not accurately reflect changes in pulmonary artery pressures and/or pulmonary vascular resistance. In normal newborns, the mean velocity of circumferential fiber shortening is a sensitive index of left ventricular function. This measure of ventricular function has not been angiographically validated in infants with PPHN. Although it is not possible to predict echocardiographically the individual contribution of changes in contractility and afterload reduction in infants with PPHN, the fact that calcium infusion reduced the preejection periods of the right and left ventricle with no effect on the shortening fraction or the velocity of circumferential shortening of the left ventricle suggests a vasodilating effect of calcium.

In vitro studies in experimental animals have demonstrated a dual effect of calcium in controlling vascular tone. Whereas concentrations of calcium in the physiologic range potentiate the contractile response of vascular muscle (15), elevated concentrations of calcium (in the range observed at 5 and $15 \mathrm{~min}$ after calcium infusion in this study) diminish the magnitude of contraction of smooth muscle and cause relaxation of already contracted vascular smooth muscle (16).

Drummond (4) hypothesized that the alkalosis-associated decline in pulmonary vascular resistance may, in part, be mediated by a decrease in the concentration of extracellular calcium and/ or an accompanying intracellular sequestration of calcium. This hypothesis is underscored by the fact that smooth muscle, as compared to skeletal muscle, is more susceptible to the extracellular supply of calcium because intracellular stores are of limited capacity and have to be rapidly refilled during mechanical activity (17). However, if increasing the concentration of extracellular calcium had potentiated the contractile response of the pulmonary vascular smooth muscle, we would have expected an increase in right and left preejection periods by echocardiography and a decline in oxygenation associated with an increase in right to left shunting. This is in contrast to our experimental findings on these 10 neonates.

The extent of ionized hypocalcemia in this report is consistent with our previous findings in hyperventilated infants with PPHN (3). Depletion of ionized calcium to this extent has been correlated in previous reports with significant myocardial disturbances in newborns and adults that have been corrected with the administration of calcium (18-20). Mirro and Brown (21), using a study design similar to that of this report, showed that rapid bolus calcium infusions significantly shortened left ventricular preejection periods in preterm infants with hypocalcemia (total serum calcium $<7 \mathrm{mg} / \mathrm{dl}$ ). Henrich, et al. (22) were able to show that the increase in ionized calcium after hemodialysis in adult patients with chronic renal failure was responsible for an improvement in left ventricular contractility. Our group of infants had very low ionized calcium concentrations and evidence of myocardial dysfunction before calcium infusion. Although the primary effect of rapid calcium infusion was to shorten the preejection period with no effect on ejection times and shortening fraction of the left ventricle, an improvement in myocardial performance that resulted in better oxygenation and reduced systolic time interval ratios cannot be excluded.

This study provides evidence that rapid correction of hypocalcemia in newborns with PPHN has no deleterious effect on the alkalosis-mediated decline in pulmonary vascular resistance and transiently improves myocardial performance and oxygenation. Further studies will be directed at attempting to sort out the effects of calcium on contractility and vascular resistance, and the effect of maintaining serum calcium by sustained infusions.

\section{REFERENCES}

1. Drummond WH, Peckham GJ, Fox WW 1977 The clinical profile of the newborn with pulmonary hypertension. Clin Pediatr (Phila) 16:335-341

2. Drummond WH, Gregory GA, Heymann MA, Phibbs RA 1981 The independent effects of hyperventilation, tolazoline, and dopamine on infants with persistent pulmonary hypertension. J Pediatr 98:603-611

3. Watchko J, Bifano EM, Bergstrom WH 1984 Effect of hyperventilation on total calcium, ionized calcium, and serum phosphorus in neonates. Crit Care Med 12:1055-1056

4. Drummond WH 1984 Persistent pulmonary hypertension of the neonate (persistent fetal circulation syndrome). Adv Pediatr 30:61-91

5. Rowe RD, Hoffman $\Upsilon 1972$ Transient myocardial ischemia of the newborn: a form of severe cardiorespiratory distress in full-term infants. J Pediatr 81:243-246

6. Riemenschneider TA, Nielson HC, Ruttenberg HD, Jaffe RB 1976 Disturbances of the transitional circulation: spectrum of pulmonary hypertension and myocardial dysfunction. J Pediatr 89:622-625

7. Bucciarelli RL, Nelson RM, Egan EA, Eitzman DV, Gessner IH 1977 Transient tricuspid insufficiency of the newborn: a form of myocardial dysfunction in stressed newborns. Pediatrics 59:330-337

8. Valdes-Cruz LM, Dudell GG, Ferrara A 1981 Utility of M-mode echocardiography for early identification of infants with persistent pulmonary hypertension. Pediatrics 68:515-525

9. Halliday H, Hirschfeld S, Riggs T, Liebman J, Fanaroff A 1978 Echocardiographic systolic time intervals in normal term and preterm neonates. Pediatrics 62:317-322 
10. Kavey RE, Krongrad E, Gersony WM 1980 Perioperative echocardiographic evaluation of cardiovascular function: assessment of changing hemodynamic state. Circulation 62:773-782

11. Milstein JM, Bennett SH 1987 Increased right ventricular afterload alters left ventricular function in newborn lambs. Am Heart J 114:369-377

12. Sahn DJ, Deely WJ, Hagan AD, Friedman WF 1974 Echocardiographic assessment of left ventricular performance in normal newborns. Circulation 49:232-235

13. Bett JM, Fraser GP 1959 A rapid micro method for determining serum calcium Clin Chim. Acta 4:346-356

14. Chen PS, Toribara TT, Warner H 1956 Micro determination of phosphorus. Anal Chem 29:1756

15. Bohr DF 1963 Vascular smooth muscle: dual effect of calcium. Science 139:597-599

16. Webb RC, Bohr DF 1978 Mechanism of membrane stabilization by calcium in vascular smooth muscle. Am J Physiol 235:C227-C232

17. Fleckenstein A 1977 Specific pharmacology of calcium in myocardium, cardiac pacemakers, and vascular smooth muscle. Ann Rev Pharmacol Toxicol 17:149-66

18. Troughton O, Singh SP 1972 Heart failure and neonatal hypocalcemia. $\mathrm{Br}$ Med J 4:76

19. Giles TD, Iteed BJ, Reves KL 1981 The cardiomyopathy of hypoparathyroidism. Chest 79:225-229

20. Bashour T, Basha HS, Cheng TO 1980 Hypocalcemic cardiomyopathy. Chest 78:663-665

21. Mirro R, Brown DR 1984 Parenteral calcium treatment shortens the left ventricular systolic time intervals of hypocalcemic neonates. Pediatr Res 18:71-73

22. Henrich WL, Judson JM, Nixon JV 1984 Increased ionized calcium and left ventricular contractility during hemodialysis. N Engl J Med 310:19-23 